\title{
Epitope-positive truncating MLH1 mutation and loss of PMS2: implications for IHC-directed genetic testing for lynch syndrome
}

\author{
Israel Zighelboim · Matthew A. Powell · Sheri A. Babb · Alison J. Whelan • \\ Amy P. Schmidt $\cdot$ Mark Clendenning $\cdot$ Leigha Senter $\cdot$ Stephen N. Thibodeau • \\ Albert de la Chapelle · Paul J. Goodfellow
}

Published online: 12 August 2009

(C) The Author(s) 2009. This article is published with open access at Springerlink.com

\begin{abstract}
We assessed mismatch repair by immunohistochemistry (IHC) and microsatellite instability (MSI) analysis in an early onset endometrial cancer and a sister's colon cancer. We demonstrated high-level MSI and normal expression for MLH1, MSH2 and MSH6. PMS2 failed to stain in both tumors, strongly implicating a PMS2 defect. This family did not meet clinical criteria for Lynch syndrome. However, early onset endometrial cancers in the proband and her sister, a metachronous colorectal cancer in the sister as well as MSI in endometrial and colonic tumors suggested a heritable mismatch repair defect. PCR-based direct exonic sequencing and multiplex ligation-dependent probe amplification (MLPA) were undertaken to search for
\end{abstract}

I. Zighelboim $(\varangle) \cdot$ M. A. Powell · S. A. Babb .

P. J. Goodfellow

Division of Gynecologic Oncology, Department of Obstetrics and Gynecology, Washington University School of Medicine and Siteman Cancer Center, 4911 Barnes Jewish Plaza,

Box 8064, St. Louis, MO 63110, USA

e-mail: zighelboimi@wustl.edu

\section{A. J. Whelan}

Department of Internal Medicine, Washington University School of Medicine and Siteman Cancer Center, St. Louis, MO 63110, USA

\section{A. P. Schmidt · P. J. Goodfellow}

Division of Endocrine and Oncologic Surgery, Department of Surgery, Washington University School of Medicine and Siteman Cancer Center, St. Louis, MO 63110, USA

M. Clendenning $\cdot$ L. Senter $\cdot$ A. de la Chapelle

Human Cancer Genetics Program, Comprehensive Cancer

Center, The Ohio State University, Columbus, OH 43210, USA

S. N. Thibodeau

Department of Laboratory Medicine and Pathology,

Mayo Clinic, Rochester, MN 55905, USA
PMS2 mutations in the germline DNA from the proband and her sister. No mutation was identified in the PMS2 gene. However, PMS2 exons 3, 4, 13, 14, 15 were not evaluated by MLPA and as such, rearrangements involving those exons cannot be excluded. Clinical testing for MLH1 and MSH2 mutation revealed a germline deletion of MLH1 exons 14 and 15. This MLH1 germline deletion leads to an immunodetectable stable C-terminal truncated MLH1 protein which based on the IHC staining must abrogate PMS2 stabilization. To the best of our knowledge, loss of PMS2 in MLH1 truncating mutation carriers that express MLH1 in their tumors has not been previously reported. This family points to a potential limitation of IHC-directed gene testing for suspected Lynch syndrome and the need to consider comprehensive MLH1 testing for individuals whose tumors lack PMS2 but for whom PMS2 mutations are not identified.

Keywords Lynch syndrome - Testing ·

Microsatellite instability · Immunohistochemistry ·

Mismatch repair genes · MLH1 · PMS2

\author{
Abbreviations \\ IHC Immunohistochemistry \\ MSI Microsatellite instability \\ MLPA Multiplex ligation-dependent probe amplification \\ RACE Rapid PCR amplification of the $3^{\prime}$ cDNA end
}

\section{Introduction}

Lynch syndrome, also known as hereditary non-polyposis colorectal cancer syndrome, is characterized by autosomal dominant cancer susceptibility in which mutation carriers are at high risk for colon, endometrial, gastric, 
small intestine, billiary, pancreatic, brain and urinary tract tumors [1, 2]. Lynch syndrome is genetically heterogeneous. Families segregate mutations in one of four DNA mismatch repair genes: MLH1, MSH2, MSH6 or PMS2. Tumors arise subsequent to loss of the wild-type allele. Loss of DNA mismatch repair in these tumors leads to a mutator phenotype. The vast majority of cancers in Lynch syndrome mutation carriers exhibit microsatellite instability (MSI) and show loss of one or more mismatch repair protein [3].

Clinical diagnostic criteria were originally designed to identify Lynch syndrome among patients with colorectal cancer. These clinical screening strategies have proved unreliable among women with endometrial cancer $[1,4,5]$. Different test methodologies have been employed to screen for Lynch syndrome using some combination of MSI analysis, immunohistochemical staining (IHC) as well as MLH1 promoter methylation assessment and family history ascertainment as means to better characterize cases and direct diagnostic testing in at risk individuals $[1,6]$.

\section{Patients and methods}

Since 1993 our group has prospectively enrolled patients with newly diagnosed uterine cancer in a study of defective DNA mismatch repair. Participants have consented to family history and molecular analyses as part of Washington University School of Medicine's Human Research Protection Office approved protocols (HRPO 93-0828). Detailed familial history is collected from participants with apparent familial cancer predisposition (based on early onset disease, familial aggregation or known synchronous or metachronous malignancies associated with Lynch syndrome). The family history data is obtained by a genetic counselor (S.A.B.). Three-generation pedigrees are developed and periodically updated. Medical record confirmation is sought for all malignancies. The process and accuracy of cancer reporting by a subset of these probands has been previously described [7, 8].

Our general testing strategy for molecular characterization of these cases includes up-front MSI typing followed by MLH1 methylation analysis. Microsatellite analysis is performed using the five National Cancer Institute consensus panel markers (BAT25, BAT26, D2S123, D5S346 and D17S250) as previously described $[9,10]$. MLH1 promoter analysis by the COBRA method is then undertaken to characterize the methylation status of the promoter region of MLH1 [10, 11]. Cases with highlevel MSI that do not have evidence of MLH1 promoter methylation are further characterized by IHC for MLH1, MSH2, MSH6 and/or PMS2 as indicated. IHC is performed using 4-5 $\mu \mathrm{m}$-thick sections from paraffin-embedded tumor tissues. Tissues are stained as previously described using the following antibodies: MLH1 clone G168-728 (PharMingen, San Diego, CA), MSH2 clone FE11 (Oncogene Science, Cambridge, MA) and PMS2 clone A16-4 (BD Pharmingen, San Diego, CA) [12, 13]. Directed mutation analysis is then undertaken. PMS2 gene analysis is carried out via exonic sequencing and multiplex ligationdependent probe amplification (MLPA) as previously described [13-16].

\section{Results}

We identified a family (kindred 1637) in which early onset endometrial cancer in two sisters along with metachronous colorectal cancer in one of them suggested genetic predisposition (Fig. 1). This family did not meet clinical criteria (Amsterdam I/II or Bethesda) for Lynch syndrome [4, 5]. Microsatellite analysis was performed on the proband's (III-1) endometrial cancer and the sister's (III-2) colon cancer. Analyses revealed high-level MSI in both tumors. MLH1 promoter analysis by the COBRA method was then undertaken on the proband's (III-1) endometrial tumor. COBRA revealed lack of epigenetic silencing of MLH1 (e.g. unmethylated promoter).

IHC performed on both endometrial tumors (III-1 and III-2) as well as the colon tumor (III-2) demonstrated lack of immunodetectable PMS2 with normal expression of MLH1 and MSH2 (Fig. 1, panel). Our IHC findings (MLH1-positive and PMS2-negative by IHC) strongly implicated PMS2. Therefore, the PMS2 gene was analyzed via exonic sequencing and MLPA. No mutations in PMS2 were identified. However, because exons 3, 4, 13, 14 and 15 were not evaluated by MLPA, deletion of these exons could not be excluded. Subsequent clinical testing for MLH1 and MSH2 mutation identified a germline deletion of MLH1 exons 14 and 15.

\section{Discussion}

MLH1 and PMS2 form a heterodimer (MutL $\alpha$ ) which plays a pivotal role in the function of the mismatch repair complex. The carboxyl-terminal domain of MLH1 is necessary for MLH1-PMS2 interaction and PMS2 stabilization. PMS2 levels are consequently undetectable or very low in MLH1-deficient cells [12, 17, 18]. Most MLH1 defects result in the complete loss or markedly reduced levels of immunodetectable protein and secondary loss of PMS2. The exon 14/15 MLH1 germline deletion identified in this family results in an epitope-stable carboxyl-terminal truncated MLH1 protein lacking the more C-terminal PMS2 interacting domain. Based on the loss of PMS2 in 
Fig. 1 Kindred 1637: I-1 colon cancer, age unknown; I-2 lung cancer, age unknown; I-3 leiomyosarcoma, died at age 54; II-1 transitional cell carcinoma of the bladder (microsatellite stable), diagnosed at age 56; III-1 endometrioid endometrial carcinoma, diagnosed at age 48 (MSI+; IHC: PMS2 absent, normal MLH1 and MSH2); III-2 MSI+ adenocarcinoma of the colon (MSI+; IHC: PMS2 absent, normal MLH1 and MSH2), diagnosed at age 45 and endometrioid endometrial carcinoma (MSI+; IHC: PMS2 absent, normal MLH1 and MSH2), diagnosed at age 53. Panel: Representative immunostains in III-2's endometrial cancer demonstrate normal expression of MLH1 and MSH2 as well as absence of PMS2. MSI+: High-level microsatellite instability. IHC: Immunohistochemistry

\section{Kindred 1637}

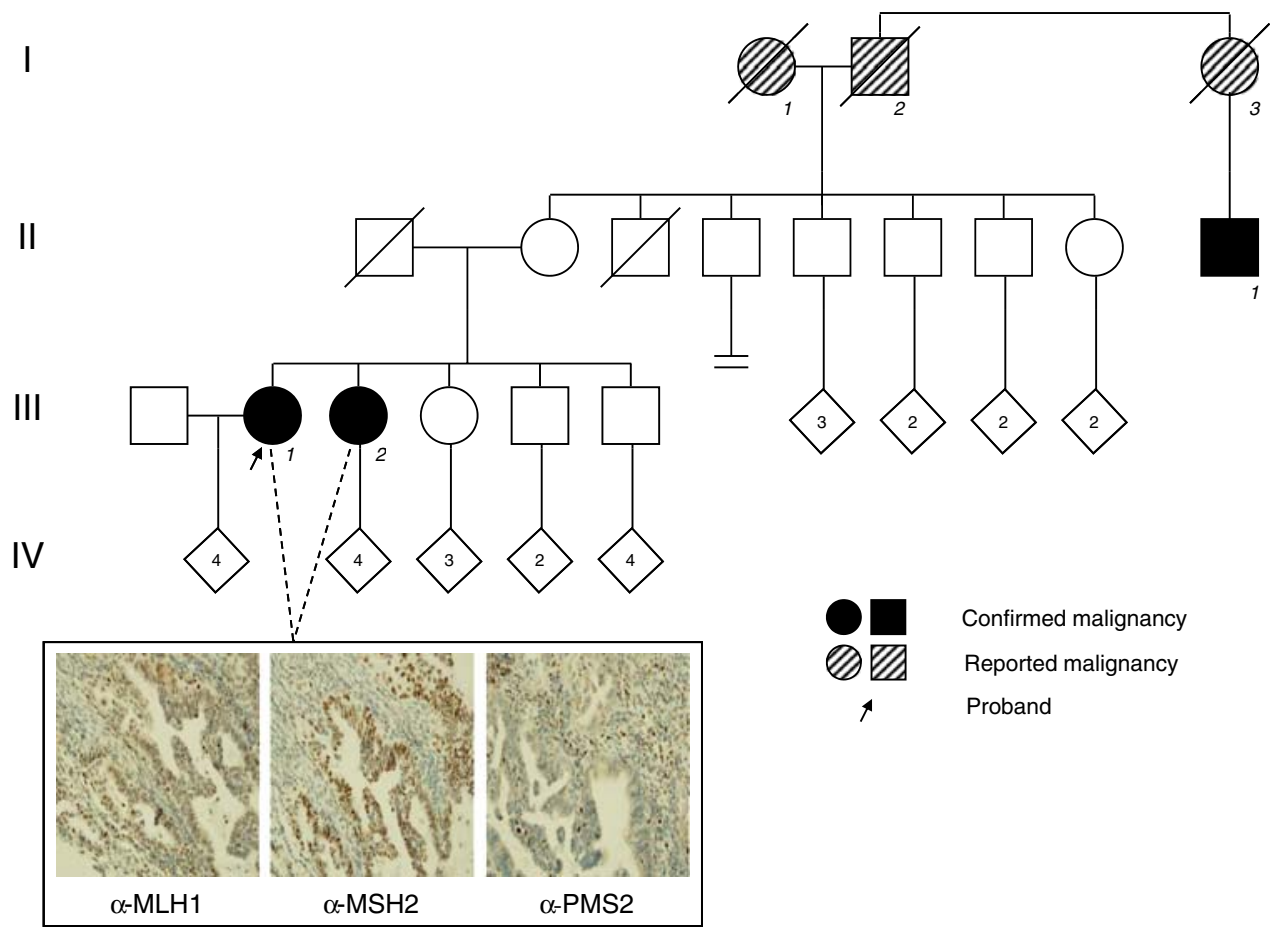

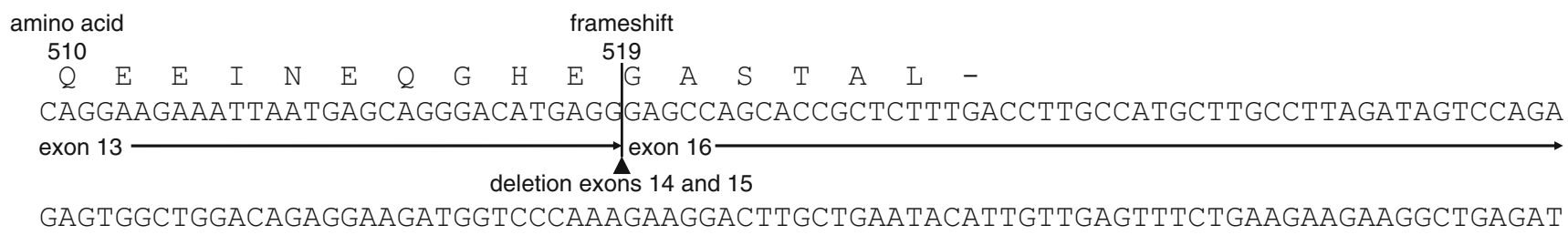

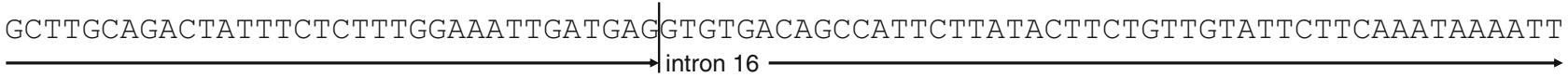

TCCAGCCACTGTGGCCGGCATtAAgTATGAgTTTTAAgTTAGCCCACTTTGTTAATGACTATGAGTACTAATAGCTTAAG

ATAAAGAAGTTTCTAGGTAATCTTGTTTGAAGGATGATGTAAAAATATAAATTTAAACTGTGAGTGACAAAATAAACTTCC

TTAАTATTTGCCTACAAАAАAАAАAАAАAАA

poly $A$ tail

Fig. 2 RACE analysis. Sequence demonstrates deletion of exons 14 and 15 and a transcript with read through to intron 16, a frameshift and stop

three different tumors arising in two carriers of this mutation, we conclude that this abnormal MLH1 protein fails to stabilize PMS2. Western blot analysis of cell lysates from the proband's endometrial primary tumor and the probands and sister's peripheral blood leukocytes revealed only the truncated protein $(\sim 58 \mathrm{kDa})$ in the primary endometrial tumor whereas the peripheral blood leukocytes demonstrated expression of both the wild type protein $(84.6 \mathrm{kDa})$ and the truncated form (data not shown). This truncated form of MLH1 was not present in a microsatellite stable endometrial tumor and peripheral blood leukocytes from healthy volunteer controls.

To further characterize the effects of the deletion of exons 14 and 15 we performed rapid PCR amplification of 
the $3^{\prime}$ cDNA end (RACE). The RACE analysis confirmed deletion of exons 14 and 15 with a transcript that resulted in a premature stop and read through to intron 16 (Fig. 2).

The loss of PMS2 expression in MSI-positive tumors is most frequently accompanied by loss of stabilization and immunodetection of its heterodimeric partner MLH1. Most of these cases will occur as a result of MLH1 promoter methylation or less frequently germline mutations in MLH1. Conversely, cases that (like our proband's) show loss of PMS2 with retained MLH1 expression point towards potential deleterious mutations in PMS2. Nakagawa and colleagues have previously identified a missense mutation in MLH1 associated with a similar immunohistochemical finding [13].

The kindred we report represents an interesting case study in that to our knowledge this is the first description of such variant Lynch syndrome family in which secondary loss of PMS2 is caused by an epitope-stable truncating MLH1 mutation. Cases like this point to a potential limitation of IHC-directed screening for Lynch syndrome and the need to consider comprehensive MLH1 testing for individuals whose tumors lack PMS2 but for whom PMS2 mutations are not identified.

Acknowledgments Supported by RO1 CA71754 (P.J.G.) and Barnes-Jewish Foundation 00161-0806 (P.J.G.). The Siteman Cancer Center is supported by NCI Cancer Center Support Grant P30 CA91842. The Ohio State University Comprehensive Cancer Center is supported by NCI Cancer Center Support Grant P30 CA16058.

Open Access This article is distributed under the terms of the Creative Commons Attribution Noncommercial License which permits any noncommercial use, distribution, and reproduction in any medium, provided the original author(s) and source are credited.

\section{References}

1. Hampel H, Frankel W, Panescu J et al (2006) Screening for lynch syndrome (hereditary nonpolyposis colorectal cancer) among endometrial cancer patients. Cancer Res 66:7810-7817

2. Aarnio M, Sankila R, Pukkala E et al (1999) Cancer risk in mutation carriers of DNA-mismatch-repair genes. Int J Cancer $81: 214-218$

3. Boland CR, Koi M, Chang DK et al (2008) The biochemical basis of microsatellite instability and abnormal immunohistochemistry and clinical behavior in lynch syndrome: from bench to bedside. Fam Cancer 7:41-52
4. Rodriguez-Bigas MA, Boland CR, Hamilton SR et al (1997) A national cancer institute workshop on hereditary nonpolyposis colorectal cancer syndrome: meeting highlights and Bethesda guidelines. J Natl Cancer Inst 89:1758-1761

5. Vasen HFA, Watson P, Mecklin J-P et al (1999) New clinical criteria for hereditary nonpolyposis colorectal cancer (HNPCC, lynch syndrome) proposed by the international collaborative group on HNPCC. Gastroenterology 116:1453-1456

6. Goodfellow PJ, Buttin BM, Herzog TJ et al (2003) Prevalence of defective DNA mismatch repair and MSH6 mutation in an unselected series of endometrial cancers. Proc Natl Acad Sci USA 100:5908-5913

7. Ivanovich J, Babb S, Goodfellow P et al (2002) Evaluation of the family history collection process and the accuracy of cancer reporting among a cohort of women with endometrial cancer. Clin Cancer Res 8:1849-1856

8. Zighelboim I, Babb S, Gao F et al (2007) Excess of early onset multiple myeloma in endometrial cancer probands and their relatives suggests common susceptibility. Gynecol Oncol 105: 390-394

9. Boland CR, Thibodeau SN, Hamilton SR et al (1998) A national cancer institute workshop on microsatellite instability for cancer detection and familial predisposition: development of international criteria for the determination of microsatellite instability in colorectal cancer. Cancer Res 58:5248-5257

10. Zighelboim I, Goodfellow PJ, Gao F et al (2007) Microsatellite instability and epigenetic inactivation of MLH1 and outcome of patients with endometrial carcinomas of the endometrioid type. J Clin Oncol 25:2042-2048

11. Xiong Z, Laird PW (1997) COBRA: a sensitive and quantitative DNA methylation assay. Nucleic Acids Res 25:2532-2534

12. Lindor NM, Burgart LJ, Leontovich O et al (2002) Immunohistochemistry versus microsatellite instability testing in phenotyping colorectal tumors. J Clin Oncol 20:1043-1048

13. Nakagawa H, Lockman JC, Frankel WL et al (2004) Mismatch repair gene PMS2: disease-causing germline mutations are frequent in patients whose tumors stain negative for PMS2 protein, but paralogous genes obscure mutation detection and interpretation. Cancer Res 64:4721-4727

14. Clendenning M, Hampel H, LaJeunesse J et al (2006) Long-range PCR facilitates the identification of PMS2-specific mutations. Hum Mutat 27:490-495

15. Clendenning M, Senter L, Hampel $\mathrm{H}$ et al (2008) A frame-shift mutation of PMS2 is a widespread cause of lynch syndrome. J Med Genet 45:340-345

16. Nicolaides NC, Carter KC, Shell BK et al (1995) Genomic organization of the human PMS2 gene family. Genomics 30: 195-206

17. Li GM, Modrich P (1995) Restoration of mismatch repair to nuclear extracts of $\mathrm{H6}$ colorectal tumor cells by a heterodimer of human MutL homologs. Proc Natl Acad Sci USA 92:1950-1954

18. Mohd AB, Palama B, Nelson SE et al (2006) Truncation of the C-terminus of human MLH1 blocks intracellular stabilization of PMS2 and disrupts DNA mismatch repair. DNA Repair 5: 347-361 